\section{BIELA'S COMET}

$\mathrm{M}$ R. J. R. HIND has addressed the following letter to France:-

You will probably think me rather sanguine in supposing for a moment that there is a chance of re-discovering either nucleus of Biela's comet this year, when in the ordinary course of things a perihelion passage would be due. I look at the matter in this light. We know that in February 1846 a very remarkable alternation of brilliancy tonk place : that the second nucleus, bareiy discernible at first, so greatly increased its light as to surpass what I will term the parent-nucleus, and continued thus several days, when it gradually faded. Again in September I 852, M. Otto Struve's drawings show the same remarkable interchange of light between the 20 th and 25 th. Whatever the cause may be, each nucleus appears to have a re-vivifying power, so to term it, and I think it is just possible this may be exercised at one time or other to such an extent as to bring the comet again within our grasp, though its condition in 1865-1866 may have been such as to render it quite invisible from the earth. In this idea of the subject, I have prepared sweeping ephemerides for September and October, part of which (that applying to next absence of moonlight and longer) I now do myself the ho nour to send you. The mean motion in Dr. Michez's orbit from 1866 would bring the comet into perihelion 1872 , October 6.4 , and I nave calculated places on this supposition, also with variations of $\pm 8^{\mathrm{d}}$ in perihelion passage. Clausen carried forward the perturbations of both nuclei in 1866 , and his elements for that year would indicate (of course, neglecting perturbation 1866-1872) the following times of perihelion passage.

Nucleus I • . I872 Oct. 4776 Greenwich

$$
\text { Nucleus II. . ", Oct. } 7: 256 \text {," }
$$

and hence these differences of R. A. and N. P. D. between the two nuclei, which, if one is only found, might be useful in bring. ing to light the other.

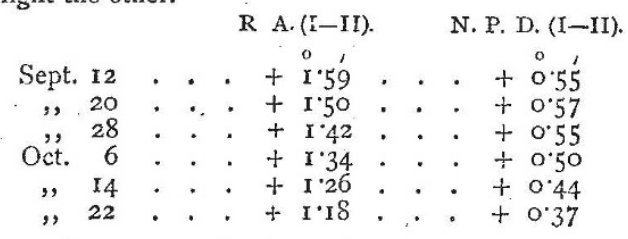

Perhaps there may yet be time to interest some of your many correspondents in a search for Biela during the first ten days of October. Here the weather has been exceedingly unfavourable, and, though I have watched assiduousiy, there has not been a single opportunity of examining the eastern heavens in the morning during the last period of absence of moonlight.

I remain, etc

J. R, HIND

Observatory, Twickenham, near London, Sept. I7

\section{SWEEPING EPHEMERIDES FOR BIELA's COMET}

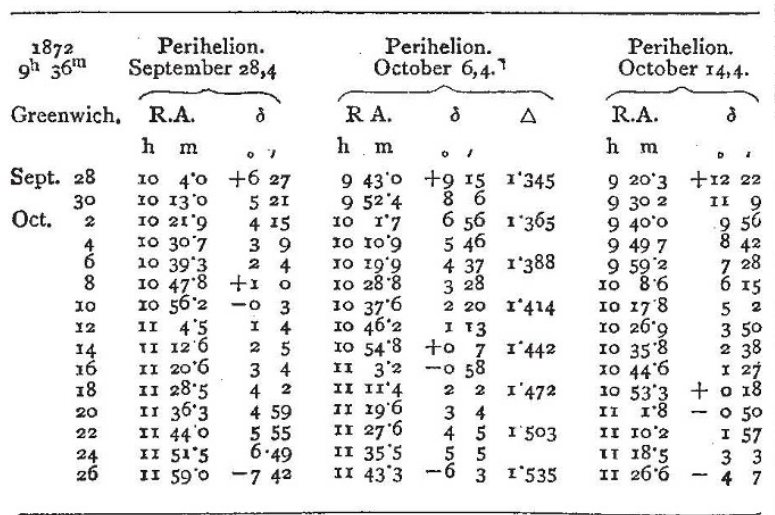

Mr. Hind, in a letter with which he has favoured us, states that M. Stephan, the Director of the Observatory of Marseilles, will employ the large Foucault mirror of that establishment in a search for the comet.

\section{AMERICAN ASSOCIATION FOR THE AD- VANCEMENT OF SCIENCE}

THE session of this Association opened at Dubuque, Iowa, on August 2r. At the end of last year's meeting it was expected that the Association would meet this year at San Francisco, which place it was hoped Prof. Agassiz would have reached in the Hassler by the time of the opening, and added an unusual brilliancy to the proceedings by an account of some of his discoveries in the Southern seas. The great naturalist, however, as we know, has not yet reached the Californian coast; and partly on this account, but mainly, we believe, on account of the great expense to most of the members of a journey to San Francisco, that city has not this year been honoured with the presence of the associated savans of the United States. Indeed, if we may judge by the somewhat diminished attendance, and the unusually small number of papers read, even Dubuque seems to be too far away from the homes of many of the members. Some of the prominent members of the American Association were absent this year, the many, however, who did attend, met with a very liberal reception from the citizens of Dubuque.

The retiring president of the last year, Prof. Asa Gray, of Cambridge, Mass., made, as is the custom, a valedictory address. $\mathrm{He}$ took the opportunity to sketch his recert experience at the West as a botanist, for, strange to say, until the present summer he had not seen the Mississippi nor set foot upon a prairie. Prof. Gray touched lightly upon the history of the Sequoias; that their age must be counted by hundreds of years we cannot doubt; but also we cannot doubt that they did not antedate the glaciers whose icy expanses have left their indisputable evidences everywhere around. The main portion of Prof. Gray's address was devoted to showing the probability that certain trees of the present day, the Sequoias of California, the Taxodium, or Bald Cypress of the Atlantic, and the Glyptostrobus, a Chinese tree, the only ones of their tribe at present existing, were not only closely allied in structure and general characteristics, but were the lineal successors by gradual modification of the fossil trees of geological ages ; and that all our existing vegetation was a continuation of that of the Tertiary period. Three hypotheses are open to account for their present existence : either they were created in the detached regions where they are now found; or they are the first members of a new and increasing race; or they are nearly the last representatives of a once powerful and widely-spread tribe. After discussing the first two alternatives, Prof, Gray gives his reasons, which are supported by palæontological evidence, for believing that the "big trees" of California are the last of their race, and that a little further drying up of the climate, which is now in progress, will speedily precipitate their doom. The oldest of the trees now standing he considers to possess an antiquity of about 2,000 years.

A paper was read by Prof. E. S. Morse "On the Oviducts of the Brachiopods." He brought forward for the first time a few facts regarding the development of a species of Brachiopod from the coast of Maine. The various stages in their development, he believed, fully supported the position he maintained, that the Brachiopods were true worms and not molluscs.

Prof. Benjamin Peirce, Superintendent of the United States Coast Survey, gave an exceedingly interesting account of the measures taken by that Bureau with reference to stations for astronomical observations at great heights, such as Sherman, on the Rocky Mountains. Prof. Young, of Dartmouth College, has been appointed to examine and give an opinion as to the effect of taking observations from the Rocky Mountains and Sierra Nevadas. Prof. Peirce's opinion was that observatories should be placed on the summits of both, if not permanently at least temporarily, the Rocky Mountains being favourable to some, the Sierra N evadas more favourable for other observations. In a higher position you get rid of absorption of light by getting rid of half the 
atmosphere. Prof. Young reports the whole number of lines in the chromosphere seen from Sherman as 150 , which is three times as great a number as have been observed before. This fact alone shows that higher points should be resorted to for astronomical observations. The next element of success depends upon the steadiness of the atmosphere. It can be said in reference to this, that a star has been recognised at these high altitudes as having a companion, or being a double star, not previously known as such. An observer on the Pacific coast reports to Prof. Peirce that he can see the companion of the star Polaris from a high point on the Sierra Nevada. It is well known that this is a test of great nicety, requiring the utmost purity of atmosphere. The best work in astronomy is done in the few best nights at any place, and by these alone the value of the position must be determined.

Prof. Peirce showed that the necessities of the Coast Survey extended its operations to all parts of the United States. To prove the paths by which vessels can best traverse the ocean, to test the best methods by which $2,000,000,000$ dollars of values shall be carried from the West to the East, from the East across the Atlantic, or from the shores of China and Japan to the Pacific coast, and thence across the country, was the business of the Coast Survey. All the United States is deeply interested in every part of the subject. Every ship that is lost by imperfectly surveyed harbours is a loss to the whole country. If the coast survey were thorough, and maps were fully representative of ascertained facts, a pilot would scarcely be necessary, but yet never could be entirely dispensed with, especially in bad weather, The pilots discovered that by putting down every rock that they knew of, they made maps that frightened the captains of vessels into employing them. Hence these practical observers have added immensely to the number of facts accumulated by the Coast Survey.

Prof. Peirce explained why he considered it unnecessary to carry out at present so thorough a survey of the Pacific as has been made of the Atlantic coast. The needs of the commerce of the coast is the standard by which the work of the survey is determined. He took oceasion to mention that the Hassler experlition was at the expense of private individuals, principally of Boston, and was not at the expense of the Government. A general geodetic connection has been effected in these observations, so that the whole United States will benefit by them; and the points will be taken so as eveniually to procure a complete survey of the whole continent, passing through each State and the large cities. It is a work that may take a century. It is the hope of Prof. Peirce that this survey will not only be the best in the world, but that its details will be such that before long there will be no necessity for railroad surveys - the facts will be spread everywhere. As to the higher operations of the Coast Survey, their ultimate expression will be an accurate determination of the figure of the earth. Observations in America he thinks are more successful and free from local irregularities than in Asia or Europe. Yet. there are some such local irregularities herenotably one ncar Boston, where there is some strange deviation of density from the surrounding country.

Prof. J. W. Foster, of Chicago, read a paper on what he considers a new species of fossil elephant, called by him Elcphas Mississippiensis. He presented to the association a fossil tooth found in Indiana, and which he regards as differing specifically from that of any other fossil elephant found in America or on the Continent. The differences are so great that he holds them sufficient to constitute the new species.

Prof. J. E. Parry, who had been in a good position for studying the subject, made a few remarks upon the glacial deposits of Northern Ohio. Prof. Foster took exception to several of his positions.

$A$ very interesting paper was read "On the Mounds of Dubuque and vicinity."

A somewhat warm discussion took place on the 23 rd between Dr. F. If. Day of Wisconsin and Prof. Morse of Salem, occasioned by the former sending a paper to prove that the trilobite not only resembled the lobster in some respects, but was actually closely related to that crustacean, and must have been in structure and movements almost similar. Prof. Morse stoutly maintained that the congener of the trilobite at the present day was the Limulus, not the lobster.

On the same day Prof. F. W. Putnam of Massachusetts, editor of the Naturalist, read a brief and well illustrated paper on certain "Stone Carvings of the New England Aborigines."

Prof. E. B. Andrews of Ohio, the State Geologist, presented a paper on Coal, of both scientific and practical interest. The universal law of the accumulation of coal strata seems to be on horizontal lines, determined by water levels. The proof of this is in the marine organic remains found in the coal itself and its associated slates. In addition, there is a distribution through seams of coal of horizontal layers of fine sedimentary matter which constitute the clay partings of the seams. The subsidence which carries down the area of the coal-marsh, if it may be so called, is wide-spread in its character and equable in its movement, having a tendency to a continental rather than a local character. The result of this gives a horizontal parallelism to all the seams of coal at the time of their formation; and this is equally true where one coal-marsh is formed over another, making a series of coal measures. So far as Prof. Andrews's observation goes, a coal seam has never been accumulated on high grounds or ground above water-level; and such formations could not take place, because it would be impracticable to establish the conditions of accumulation on the side of a hill. Hence it is impossible in the nature of things that two distinct seams of coal could ever coalesce, since their subsidences must take place in parallel lines. To suppose otherwise would involve a very un. equal subsidence over very limited area, amounting, indeed, to a convulsion of nature, which is almost incredible.

It has hitherto been to some extent conceded that the solidification of coal is an exceedingly slow process; and the popular notion is that there has been a complete accumulation of a series of layers of coal, \&c., long before thorough hardening takes place. Prof. Andrews has, however, found instances indicating that the process of solidification, making complete coal, is comparatively rapid. Thus it appears that where a gulley has been torn out of a coal seam by a rapid current of water, the small boulders washed by it over the covering stratum of sand a few feet above, are complete coal, having an angular fracture, some being still sharp on the edges and some being slightly water-worn. These boulders in turn have again been covered by subsequent depositions, and are found at considerable depths, near the base of the coal measures.

There are three leading varieties of bituminous coal ; the ordinary resinous or caking coal, the splint, and the cannel coal. These pass into each other by almost imperceptible yradations. The resinous coal seems to be the normal condition which the buried vegetation first assumes, and splint and cannel are modified forms, the canniel coal having lost all trace of structure, and containing no organised forms, except stigmaria, which is very abundant. The ash of coals is the original inorganic matter of vegetation, often increased by sedimentary matter in the marsh churing the formation of coal.

Prof. C. A. White, of Iowa City, gave a general sketch of the geology of the State of Iowa, in which he stated that the extent of its coal measures was greater than the entire area of Massachusetts. The occurrence of quartzite in the north-eastern portion of Iowa he regards as of the l'otsdam formation. There is a remarkable area of drift in the north-western part of the State, covering an area of at least 20,000 square miles so deeply that no rock crops through. Prof. Swallow thinks that the waters receding from this State went to the Pacific.

In the discussion which took place next day, on Prof. Andrews' paper, several geologists controverted his position that coal seams seldom or never diverged from each other within small areas, adducing instances to prove their statements. Prof. Andrews did not doubt that there were occasional instances of the sort, but in general he did not believe that there were frequent cases where seams separated widely. Seams of coal, as a rule, with rare ex ceptions, were of parallel levels from uniform subsidences.

On the evening of the $23 \mathrm{rd}$, Prof. Morse delivered to a large and delighted audience a popular lecture on "The Locomotion of Animals," beginning with the lowest forms of animal life, and working his way upwards through all grades to man, illustrating his statements by a series of clever and rapidly-executed illustrations on the black-board.

On the 24th, the Association passed a resolution with regard to what is known in America as "the Chinese Indemnity Fund," the name given to a large sum which China overpaid in settling for damages to United States citizens, and which, when informally tendered to the Chinese Government, was declined, with the intimation that pressure on the subject would be hurtful to Asiatic pride. This fund now amounts to 450,000 dols, and a bill is now pending in Congress which proposes to appropriate this surplus for the education of Americans and Chinese "in the languages, literatures, and sciences of the respective nations; to facilitate commercial, diplomatic and scientific intercourse be- 
tween the two peoples; and for the increase and diffusion of knowledge among men." It is apparently intended to accomplish this purpose by establishing an American college in China, and the resolution of the Aasociation "heartily endorses the purpose of the aforesaid Bill."

In expatiating upon the propriety of this resolution, President Smith alluded to the insecurity of the present position of the fund in the hands of the United States Government, since it offered a premium for trumped-up claims, and already 37,000 dols. had been thus abstracted from it; that if it remained much longer unıppropriated, Japanese as well as Chinese claims would be in'roduced against it, and it might eventually suffer the fate of the Smithsonian funds, which the Government had to make good after the loss of a considerable portion.

During the course of the same day a scene of intense excitement and disorder took place on the reading of a paper by Prof. B. C. Swallow, the Missouri geologist, entitled "Good Wine a Social and National Blessing,' which was devoted princi. pally to the details of wine making. It was, however, made an opportunity for the discussion of the causes of drunkenness, and the best means for preventing it, which had far more of a social than of a scientific interest.

A very interesting and valuable paper was that of $\mathrm{Mr}$. C. V. Riley of St. Louis, entitled "Insects Shaped by the Needs of Flowers," with especial reference to the fructification of the American Yuccas. Dr. Engleman of St. Louis had this year discovered that these plants must needs rely on some artificial agency for fertilisation. The flowers are peculiarly constructed, so that it is impossible for the pollen to reach the stigma, it being glutinous and expelled from the anthers before the blossoms open. Prof. Riley discovered that there was a small white moth that did the work, and demonstrated on the blackboard how wonderfully well the insect was adapted to the purpose. This lit le moth, which he calls Pronuba Yuccasella, has been unknown to entomologists, and forms the type of a new genus. It is ni.ust anomalous from the fact that the female only has the basal joint of the maxillary palpus wonderfully modified into a long prehensile-spined tentacle. With this tentacle she collects the pollen and thrusts it into the stigmatic tube, and after having thus fertilised the flower she consigns a few eggs to the young fruit, the seeds of which her larva feed upon. He stated that the Yucca was the only entomophilous plant known which absolutely depended for fertilisation on a single species of insect, and that insect so remarkably modified for the purpose. There was a beautiful adaptation of means to an end, and a mutual interdependence between the plant and animal ; and Mr. Riley explained how on Darwinian grounds, even this perfect adaptation was doubtless brought about by slow degrees. He alluded, in closing, to a practical phase of the subject. The plant and its fructifier are inseparable, under natural conditions, and the latter c.ciurs throughout the native home of the former. In the more northern portions of the United States, and in Europe, where cur Yuccas have been introduced and are cultivated for their show'y blossoms, the insect does not exist, and consequently the Yuccas never produce seed there. The larva of Pronuba eats through the Yucca capsule in which it fed, enters the ground and lit)ernates there in an oval silken cocoon. In this stage the insect may easily be sent by mail from one part of the world to another, and our transatlantic florists may by introducing it soon have the satisfaction of seeing their American Yuccas produce seed without any personal effort on their part.

Among other papers read at subsequent meetings of the Association was one by Dr. J. W. Foster on the "Bird-shaped Skulls found in Indian Mounds," in which he tried to show that the peculiar shape of these skulls was not produced by compression, as in the case with the heads of many modern Indian tribes, but really belonged to a very early and comparatively low type of man intellectually.

Another paper was by Pruf. Daniel Kirkwood on "Binary Stars with Extraordinary Orbits," with special reference to Mr. Wilson's communication to the Royal Astronomical Society, as to the orbits of the stars constituting Castor.

Mr. W. W. Wheildon of Concord, Mass, advanced in opposition to what is known as the Gulk Stream theory an atmospheric theory to account for ameliorations of climatc and an open sea in Polar regions. He thought that thers could be no question that if the whole Arctic region were of open water that fact would not account for all the atmospheric phenomena and warmth of temperature experienced by polar navigators. The theory of Prof. Wheildon is that open water, melting ice, rain after snow, and other phenomena of the sort in Arctic regions, are not caused by winds warmed by an open sea, but by a circulation of air in which warm winds descend from upper atmospheres; being a circulation by which winds heated at the equator reach the poles. The brief discussion which followed this paper did not indicate much difference of opinion on the subject.

Of course, there were the usual numbers of excursions to places of interest, including one to the curious "Picture" or "Calico" Rocks near the town of Macgregor, which are composed of Potsdam sandstone. Far up in a narrow glen, outcropping sandstone rocks, partially denuded, exhibit in narrow stripes and patches, but principally in linear horizontal directions, the greatest variety of colours. Red is predominant, but black, blue, yellow, and intermediate shades are not wanting, each being distinct and not unfrequently contrasting sharply with the adjoining stripe, or with a gray that is almost white. Probably the original sand was white; the colours indicate varying admixtures of iron oxides and carbonates. Another was to the Mississippi, apparently for the purpose of seeing and collecting specimens of the large lily or lotus of that river (the Nelumbium luteum), closely allied to the Egyptian lotus. The last excursion was to Sioux City, and was to last for three days.

Altogether this year's meeting seems to have given general satisfaction, and the hospitality of the Iowans was unbounded. Next year's meeting is to take place at Purtland, Maine, on the third Wednestay of August, Prof. Joseph Livesing, of Harvard University, being the president-elect.

\section{THE FRENCH ASSOCIATION MEETING AT BORDEAUX}

THE first session of the French Association for the Promotion of Science, closely modelled after that at Britain, was held at Bordeaux from the 5 th to the 12 th of September, and seems in all respects to have been successful and satisfactory. As is usual at similar meetings everywhere, the citizens of Bordeaux lavished their hospitality upon the members, who well deserved this as well as the gratitude of the French generally for inaugurating a movement to spread among that nation a knowledge of and love for science, and thus inform and temper their often misleading enthusiasm; in the words of $M$. Quatrefages, "to renovate our country by the scientific spirit and scientific studies." The meetings were well attended both by French and foreign savans, though the only two English ones whose names we notice were Prof. Odling and Dr. Gladstone. The Society already numbers 800 members, and, as will be seen by M. G. Masson's paper, its finances are in a flourishing condition. The first general meeting was presided over by M. de Quatrefages (the president-elect for next year), in room of $M$. Claude Bernard, the state of whose health prevented him from attending.

The opening address of $M$. de Quatrefages, as acting president, was a very stirring and noble one, full of sound sense as to the recent humiliation and present condition of Fraisce, $\in n$ thusiasm towards science, and faith in it as one of the most powerful regenerators of the country. "Science is at present supreme," he said ; "she is becoming more and more the sovereign of the world ;" and he believes that it is only when all ranks and classes of the people, rulers and ruled, are thoroughly imbued with the scientific spirit, and are guided by scientific knowledge, that France will ever again take and maintain the supreme place in the world which she ought to hold. M. de Quatrefages concluded with a graceful allusion to "our elder sister, the British Association."

After an enthusiastic speech from the Mayor of Bordeaux, M. Cornu gave a brief sketch of the history of the Association. The first idea of the Association, he tells us, originated among a group of French Alsatian students gathered around M. Combes, the late lamented director of the School of Mines of Paris, and it has been nourished by a patriotic idesire to contribute to the moral condition of the dejected country. After the death of $M$. 